\title{
The CoViD-19 pandemic and the end of corporate risk management as we know it
}

\section{Markus WILL}

\section{Zittau/Görlitz University of Applied Sciences, Germany}

\begin{abstract}
Aim: The article is intended to contribute to a discussion on risks related to the CoViD-19 pandemic, which was started in the last issues of this journal.

Findings: The article discusses the thesis that conventional risk management is reaching its limits in its application in companies, particularly with regard to low-probability but high-impact events its applications seems nor appropriate. In complex and tightly coupled systems like global supply chains, catastrophic events must be considered "normal". The risk of a global pandemic is well known, and at the end of 2019 the first signs of an impending outbreak were also evident. Nevertheless, the global pandemic and the gradual lockdown was surprising in that no precautionary measures were taken. Therefore, this paper argues for a change of perspective from traditional risk management to business continuity management (BCM) and for increasing the resilience of supply chains.
\end{abstract}

Keywords: CoViD-19, risk management, black swans, business continuity, supply chain resilience

\section{Introduction}

The importance of the publications of two American organizational sociologists cannot be overestimated for today's risk and crisis management. It was Charles Perrow and Karl Weick who, like few other academics, described the normality of disasters (Perrow 2011, 2004, 1992) and possible options for action (Weick 2016; Weick et al. 1999; Weick, Sutcliffe 2011). It is thanks to their insights that valuable suggestions for better management of crises and the leadership of organizations in the VUCA

Contact details: Markus Willl, Zittau/Görlitz University of Applied Sciences, Germany. E-mail: m.will@hszg.de

Received: 21.09.2020, Revised: 27.09.2020, Accepted: 28.09.2020

doi: http://dx.doi.org/10.29015/cerem.888 
environment ${ }^{1}$ can still be found today. In the face of the multiple sustainability crises, technological disruptions and the recent and ongoing CoViD-19 pandemic, it seems that conventional managerial approaches need to be adapted. Generally speaking, dealing with deviations from normal conditions is the main task of top management (Hoskisson et al. 2016; Jansen 2009; March, Shapira 1987), which requires flexible and adaptive action from decision-makers. Holding on to management instruments that have so far been promising or effective is probably the only thing that should not be normal (Jansen 2009). Karl E. Weick, therefore, advises: "Drop your tools"" (Jansen 2009; Weick 1996). Dealing with uncertainty is the big issue of our time - in everyday life as well as in politics, in personal infection protection as well as in crisis management for the coming months. CoViD-19 has made us drastically aware "Extremistan" (Taleb 2008) and its fragility in an interconnected worlds with nonlinear interactions.

CoViD-19 and the lockdown pose enormous challenges for individuals, organizations and entire societies. Currently - i.e. in September 2020 - the financial and non-financial effects cannot yet be fully described. However, it is becoming increasingly clear that the crisis management of the pandemic has succeeded to varying degrees in different parts of the world (Cheng et al. 2020; Dehning et al. 2020; Wieler et al. 2020). However, it is undisputed that CoViD-19 hit the political and economic system as well as decision-makers by surprise, although a pandemic can be considered as a normal, expected and predicted event (Platje et al. 2020; van Dam, Webbink 2020). This diagnosis led van Dam and Webbink (2020) in a reflection paper in this journal to conclude, that "the most influential decision-makers collectively and systematically deny and wilfully ignore predicted future disasters" (van Dam, Webbink 2020: 9).

The advice to "drop the tools" and the diagnosis of "wilful ignorance" refer as the starting points for this article, which aims to describe the limit of conventional enterprise non-financial risk management systems and to contribute the discussions

1 VUCA stands for volatility, uncertainty, complexity, and ambiguity (see for instance: Chawla, Lenka 2018).

2 And I mean here: not only with regard to analysis, but also the execution of management itself. 
which started in CEREM with articles from Joost Platje and fellows and Ynte van Dam and Joke F. Webbink (Platje et al. 2020; van Dam, Webbink 2020).

The logic of the argumentation is as follows: In complex and closely coupled systems, such as global supply networks, disruptions are to be considered as normal, as described by the normal accident theory (section 2). Conventional risk management and its applications often refer to a probability-based approach and should allow thresholds for intervention to be set based on cost-benefit analyses. This approach to risk management is referred to as "conventional risk management" in this paper, and its limitations are described (section 3). Section 4 deals with the description of the pandemic as a "black elephant", i.e. a foreseen but ignored risk, and as a wicked problem. This leads to further insights into the limitations of conventional risk management. Finally, this paper advocate for changing the perspective from causes and their probability towards a more preventive approach. Business continuity considers critical processes for deriving measures for rapid recovery and restart.

\section{Normal disasters}

The more complex the effects between system components and the closer the coupling of system elements, the more "normal" or inevitable disasters become (Perrow 2011, 2004, 1992). The term "normal" is by no means a statement of frequency. Instead, it should indicate that particular organizational structures cause inherent system characteristics which favour accidents and make them "normal". For the description of inherent system properties, Perrow employs the two distinct categories interaction and coupling (Perrow 2011, 1992).

Interactions describe the relations between different components in a DEPOSE system (i.e. design, equipment, procedures, operators, supplies and materials, environment). A linear interaction exists if a component only interacts with a preceding or following component, as in the case of a lamp series connects or a simple assembly line. Component (a) influences component (b) and this, in turn, influences component (c) etc. Linear systems are mostly trivial, these simple interactions occur immediately and during regular operations. In case of deviations and unplanned 
operation conditions, failures can be easily detected by operators. Taking the example of the assembly line, this means that if a component or unit fails, the effects "down the line" are predictable, adverse impacts can be foreseen, and countermeasures can be planned ex-ante and initiated (Perrow 1992: $107 \mathrm{f}$.). Before the failed technical component, incoming parts are pent up. Behind it, incompletely assembled parts are carried on (Perrow 1992: 108). It is irrelevant how many steps or components the assembly line consists, be it three components or 1000 or $1,000,000$. On the other hand, there are more complex interactions in which the system components can all interact with each other. There are also external factors that influence the interaction of the system components positively or negatively. Complex interactions can be "bydesign", or they occur unexpectedly in case of failures. Complex systems are often not immediately transparent for the operating personnel. Components can have common-mode functions, i.e. see have several functions and operate two or more other components. If a malfunction of common-mode functions occurs, a variety of consequential or dependent errors occur. As the number of mutually influencing components increases, the complexity of the overall system increases and the number of possible reactive interactions no longer increases proportionally but by square or exponentially. Ramifications, feedback loops and disruptions characterize complex interactions. If each element can influence another, the effects are no longer predictable. Such highly complex systems are often controlled by cybernetic processes (including feedback loop process control).

However, due to cognitive limitations, they are difficult for humans to understand (Dörner 1997). In most cases, attempts are made to reduce complexity and keep the system linear, i.e. to mitigate or prevent unintentional complex interactions between the elements through safety precautions or buffers. Paradoxically, the preventive extension of the DEPOSE system with redundant components, one of the dominant security strategies in critical infrastructures, unfortunately, leads to an increase in complexity and thus to a reduction in security and a false sense of security (Sagan 2004).

Highly complex systems are not necessarily error-prone or fragile systems. According to Perrow, another aspect, independent from the complexity of interaction, is the coupling of elements. The concept of coupling refers to the cohesion of 
fragmented parts of a social system (e.g. an organization) and the number of mutual variables (Glassman 1973; Vester 2012; Weick 1976). Elements of an organization can therefore be coupled with tight and dense linkages or not. Closely coupled systems imply that there is no buffer zone or elasticity between two interconnected parts (or subsystems). Disturbances thus have an abrupt effect on the overall system, whose resilience is low. The processes are difficult to change, and there is no possibility of delays in the operation. Only one method and one set of resources can achieve the objectives. Loose coupling, on the other hand, allows individual parts (or subsystems) to act according to their own logic and interests. With closely coupled systems, this possibility is limited. Loosely coupled systems have no direct connections but are also not entirely independent. There is room for manoeuvre, processes can be changed, and alternative methods of achieving objectives are conceivable. Due to margins, buffers and redundancies or the possibility of substituting specific resources, delays in the operational process can be tolerated. Loosely coupled systems are therefore less prone to failure and more stable (Weick 2016).

In linear systems, close coupling is an optimal way to organize (Perrow 1992: 132). The more tightly coupled a system is, the faster and more efficient work can be done, as is to be achieved, for example, with lean management, which is popular with corporate consultants, and through just-in-time production processes (Saurin et al. 2013; Soliman et al. 2018). However, this increases the dependency on the supplier or a network of suppliers. If the right part is not delivered at the right time, the production process must be stopped. There is no room for manoeuvre; everything has to run according to plan. However, in organizations characterized by complex interactions and close interdependencies, which are likely to include globalized supply chains (Choi, Wu 2009; Dyer, Nobeoka 2000; Skilton, Robinson 2009), resilience decreases and disruptions, interruptions or disasters become more inevitable or can be considered normal. For (risk) management, this means that disturbances are virtually inevitable. Hence the determination of probabilities, which is a standard procedure in conventional risk management seems unnecessary. 


\section{Conventional risk management and its limitations}

Risk management is a framework to the more or less systemic analysis and assessment of the positive or negative impacts of particular events and activities on organizations. The aim of risk management is, according to the international management system standard ISO 31000, to acquire a proper understanding of issues involved (Zio 2018) and to take coordinated and informed decisions to control risks and to avoid adverse outcomes. Systemic understanding is expected to allow for rational management of (potentially) hazardous industrial operations. Quantitative risk assessment is, for more than 50 years now, based on the concept of (Bayesian) probability (Kaplan, Garrick 1981; Kelly, Smith 2009; Zio 2018), the frequency of occurrence and adverse impacts, i.e. the number of fatalities (Starr et al. 1976). These underlying principles, which have first been applied with regard to large technological systems, their siting and public tolerance and acceptance (Farmer 1967) are still remaining (Aven 2020; Jonkman et al. 2003). Generally speaking, risk management deals with the possibility that an event occurs which poses (typically negative, i.e. undesirable, adverse or harmful) $)^{3}$ consequences. Impacts are often described with reference to particular values, the impairment of objectives or by monetarization. In its most simplified form, risk management relies on the risk equation described as

$$
R=\text { Frequency } x \text { Impact }
$$

and the risk matrix (see Figure 1) as its graphical representation (Kaplan, Garrick 1981). The risk equation and matrix represent expected damage and estimated likeliness of occurrence of an event.

\footnotetext{
${ }^{3}$ This is at least the everyday life understanding, where risks are related to negative outcomes where as beneficial effects are typically considered a chances or opportunities.
} 


\section{Figure 1. Example of risk matrix}

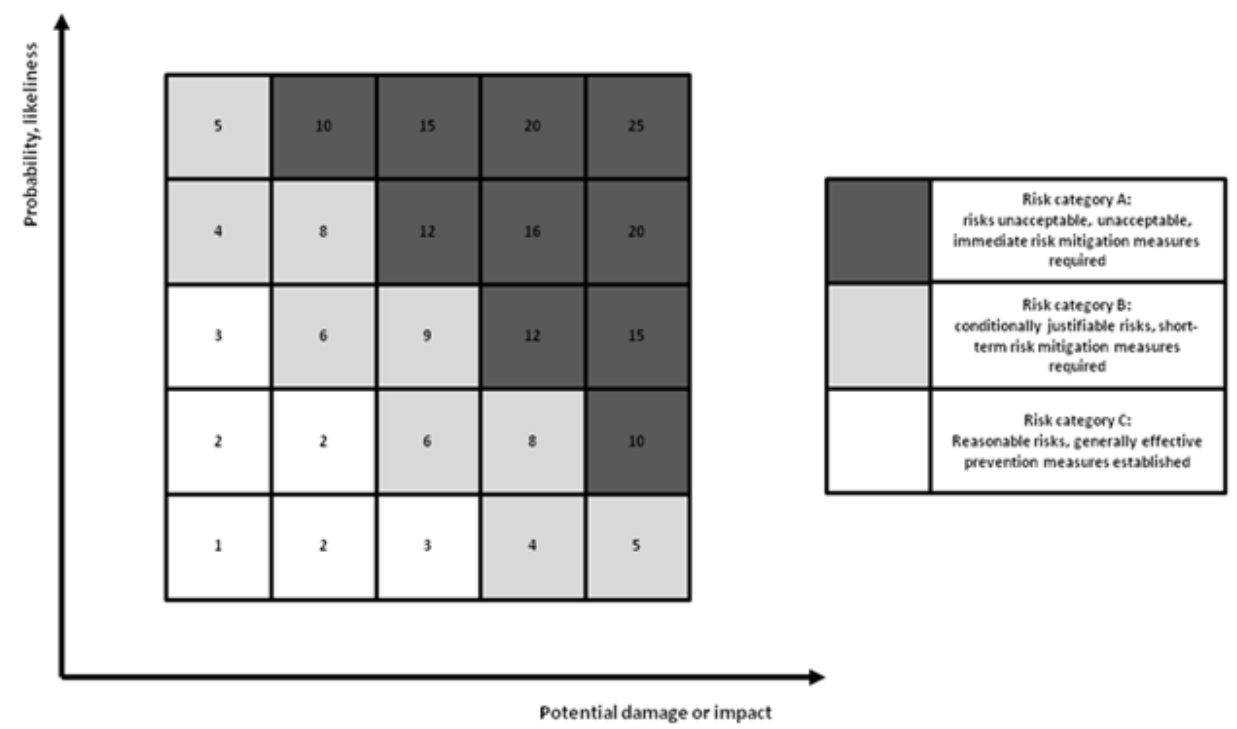

The expected damage is classified into categories by using simple ordinal scales, for example, from 'no damage' or 'minor damage' to 'very high damage'. The probability or likeliness of occurrence is estimated based on a suggested frequency in the same manner. It ranges, for instance, between 'very unlikely' to 'most likely' or 'pretty sure'. In order to derive risk mitigation measures, prioritization is necessary that characterizes the need for action. In the case of operating risks, the assigned values for damage and probability are multiplied and classified into risk priority classes by the help of thresholds. Those thresholds follow the ALARP-Principle, which stands for the minimization of risk to an acceptable or tolerable level, which is considered "as low as reasonable practicable" (Jones-Lee, Aven 2011). The ALARP principle, which was first specified as a regulatory requirement in UK's Occupational Health and Safety laws (Jones-Lee, Aven 2011; Melchers 2001), takes into account that effort and money must be spent in risk reduction, but also that spending are limited. The guiding principle is an economic one, based in cost-benefit-analysis (Ale et al. 2015). ALARP does not aim to achieve zero risks at all cost. The relation between cost and the benefit of risk mitigation may not be disproportionate from an individuals or organizations perspective. Needless to say that this perspective is 
unethical and not appropriate for societal decisions. Thresholds that separate the area of tolerable risk from the intolerable risk must be explicitly defined for each organization and context, for example:

- Risk class A: risks unacceptable, unacceptable, immediate risk mitigation measures required.

- Risk class B: conditionally justifiable risks, short-term risk mitigation measures required.

- Risk class C: Reasonable risks, generally effective prevention measures established.

Admitted, the risk formula is a straightforward and pragmatic way and why it enjoys great popularity in practice. It forces the user to apply an abstract and descriptive two-dimensional evaluation grid (i.e. index of probability and extent of damage). The result is an orientation variable that can be used in any context to rank particular actions according to their degree of risk (Renn 2007; Wilson, Crouch 2001). However, the concept was criticized mainly from social scientists for various reasons, i.e. for its application in the context of risk technologies and due to its generalization of time and place (Beck 1988, 1992a, 1992b). Due to the context-specificity and subjectivity of the procedure, requirements for objectivity cannot be met, which is why the risk formula is not suitable for use in science or politics (Douglas, Widavsky 1983; Jasanoff 1999; Perrow 2011).

This critique, however, can be countered by the fact that (1) in principle, every risk assessment is subjectively influenced and can never claim objectivity. Accordingly, there is always a need for political regulation. (2) It must be recognized that it is precisely the abstraction from the individual case to a generalized case that enables the comparison of situations and alternatives and that risks and potential dangers can be presented relative to each other. Accordingly, preference should be given to those options for action that cause the least damage, regardless of the distribution of affectedness (Renn 2007). Nevertheless, the it is advisable to reflect on the approach in order to avoid arbitrarily use and (cognitive) biases. Strictly speaking, the risk formula can only be reliably applied under certain conditions (Banse, Bechmann 2013; Ganz, Deuerler 2011): 
a) The damage event occurred very frequently and could be observed well; the retrospective view is representative and trustworthy. Only in this case, a sufficiently exact data basis can be compiled to be able to conclude from a random sample on the whole, in order to determine or extrapolate expected values for the probability.

b) For damaging events, triggering factors can be identified, and robust cause-effect chains and, at best, dose-effect relationships can be determined.

c) Subjective assessments must be justifiable, coherent and free of contradictions and thus not "arbitrary".

d) Blindness to black swans cannot be excluded; even reliable systems bear risks (i.e. if complex and closely coupled).

Two of the aspects, ( $a$ and d), mentioned above will be explained in more detail at this point. Firstly, for the estimation of the frequency and the probability of occurrence, reliable data and information are needed. This sort of information relates either to the historical events or is just a subjective guess on future likelihood. The latter is highly speculative and subjective. However, also the view into the past is deceptive, as has long been known in the philosophical criticism of naïve inductivism (Chalmers 2013; Hume 1993; Russell 2004, 2001). Induction relates to the derivation of general knowledge based on observations, i.e. the analysis of past events. Inductive confidence grows with the number of observed events, and so does the feeling of security, but in the most remarkable security, it is also most dangerous. For illustration, the story of the "inductivist turkey" is often presented: A farmer feeds a turkey every day. Before concluding based on only a few observations, the turkey collects data for a longer period taking into account different circumstances. Following the concept of induction, the turkey concludes this will continue, so the turkey develops a feeling of security and reliability that it will be well treated and fed every day. The turkey inductively concludes from the past to the future. Suddenly the turkey's throat is cut on Thanksgiving Day (Chalmers 2013, relying on Russell 
$2001)^{4}$. The end of the story is simple: it does not matter how many events or cases are observed in the past as nothing can guarantee that the next case will follow this particular trajectory.

Another problem of inductive reasoning, especially concerning risk management, is the black swan fallacy. The metaphor of the black swan was coined, besides others, by Karl Popper and his concept of falsification (Popper 2002). In another context N.N. Taleb has used the term, namely regarding extremely unlikely (improbable) events with large-scale and disruptive impacts (Taleb 2008). These Black Swan events are nearly impossible to predict. Nobody thought of Black Swans (such as Fall of the Berlin Wall, the Fukushima nuclear accident, the internet revolution, etc.), and they occur surprisingly and unexpectedly ("unknown unknowns"). Indeed, humans fail to recognize black swan events or tend to ignore them - also in industrial risk management (Murphy, Conner 2012). This is due to a wide range of fallacies, such as (Pfluger 2009; Taleb 2008):

- Fade out: We pretend that there are no black swans. "Outliers" occur so rarely, is it worthwhile to take precautions and develop a corresponding perception?

- Confirmation fallacy: We concentrate on selected segments of what happened and, more generally, we focus on what we do not see.

- Tunnelling: We concentrate on defined sources of uncertainty ("known unknowns"), on a list of documented black swans (and neglect others that we do not easily think of).

- Narrative fallacy: Stories are told, the characteristic patterns follow and give us a distorted image (Platonism, "map not territory", "what we see is not what is there").

\footnotetext{
4 „Domestic animals expect food when they see the person who usually feeds them. We know that all these rather crude expectations of uniformity are liable to be misleading. The man who has fed the chicken every day throughout its life at last wrings its neck instead, showing that more refined views as to the uniformity of nature would have been useful to the chicken." (Russell 1912/2004, according to: https://archive.org/details/problemsofphilo00russuoft/page/98/mode/2up?q=Domestic+anima ls+expect+food [09.09.2020].
} 
In addition, there is another issue leading to biased risk perception, which is the paradox circumstance that we are afraid of the wrong risks. Let's call this the "white shark" effect, it means that (some) people tend to assess certain risks as very high and play down others, even though statistically those risks are very low (e.g. fear of electro smog, polluted indoor air or pesticide residues in food). These issues may pose risks, but if compared to the statistically recorded causes of death, it is evident that people are more likely to die from poor nutrition, high blood pressure, smoking or overweight (Renn 2014). A reason for the individual overestimation is that risks are social constructs (Renn 2014, 2007), which are biased by (social) media, fake-news but also personal characteristics and risk preferences that affect the perception and therefore the acceptance of risks.

This said, it becomes understandable why, despite the pragmatic preference for the risk matrix as an easy-to-use tool, the limits of the approach must be considered at least, if the tool of a risk matrix is not better dumped and replaced by more meaningful approaches. Looking at current pandemic, which can be used as an example of wicked problems, the futility of the approach can be made even more apparent.

\section{CoViD 19 pandemic: a wicked black elephant}

In the Chinese city of Wuhan (Hubei Province), a new and unknown form of pneumonia was detected end of 2019. The disease was reported to the WHO office on 31 December 2019. The Central Government of China imposed the "Wuhan Lockdown" on 23 January 2020 after the novel coronavirus to other major cities in China and other regions and countries, including Hong Kong, Macau, Taiwan, Thailand, Japan, South Korea, and the United States ${ }^{5}$. WHO officially described the Wuhan lockdown as "unprecedented in public health history" and declared a "Public

5 yin $\% 3 \mathrm{~A} \% 20 \mathrm{~W} \% \mathrm{C} 7 \% 94 \mathrm{~h} \% \mathrm{C} 3 \% \mathrm{~A} 0 \mathrm{n} \% 20 \mathrm{f} \% \mathrm{C} 4 \% 93 \mathrm{ng} \% 20 \mathrm{ch} \% \mathrm{C} 3 \% \mathrm{~A} 9 \mathrm{ng}$ [10.09.2020]. 
Health Emergency of International Concern" on 30 January $2020^{6}$. The name COVID19 was given to the novel coronavirus disease on 11 February 2020 and exactly one month later, the WHO declared a global pandemic officially, as the disease was detected on all continents (Balog-Way, McComas 2020; McAleer 2020). In the further course of time, almost all countries with detected COVID-19 cases have enforced some form of pandemic lockdown, which covered the entire country or only individual regions or cities ${ }^{7}$. The term lockdown ${ }^{89}$ was commonly used with regard to mass-quarantines or stay-at-home orders as well as closures of certain types of businesses, or bans on lager events and gatherings ${ }^{10,11}$. The lockdown was justified with the high transmissibility and the possibility of overburdening the health care systems. It was some sort of preventive lockdown because virologists and infectious disease modellers predicted large scale impacts and death tolls unless early action is taken and maintained (representative of the many studies (Adam 2020; Davies et al. 2020; Dehning et al. 2020) - an approach which was strongly criticized at an early stage (Ioannidis 2020). The pandemic and lockdown measures have indeed impacted global economies and supply chains. Predictions and scenarios are - by nature uncertain, but the outbreak already had and will have significant impacts on the global economy (Atkeson 2020; Guerrieri et al. 2020; Ludvigson et al. 2020; McKibbin, Fernando 2020; Nicola et al. 2020). According to predictions by the IMF, the global GDP will decrease by $4.9 \%$ in 2020 , with an average annual change of $-8 \%$ in the US and $-10 \%$ in the Eurozone, and $-3 \%$ in emerging markets and developing economies (IMF, 2020). The NBER predicted a cumulative loss in industrial production of $20 \%$ and in service sector of nearly $39 \%$ for the US for 2020 to 2021 (Ludvigson et al. 2020). The IMF also projects that recovery will be gradual, taking into account that the pandemic is a global and multi-period event. However, global GDP growth is

\footnotetext{
${ }^{6}$ However, the Spanish Flu and Black Death are examples where governing bodies also took radical measures in different places, though not globally at the same time.

${ }^{7}$ https://en.wikipedia.org/wiki/COVID-19_pandemic_lockdowns [10.09.2020].

8 https://www.businessinsider.com/countries-on-lockdown-coronavirus-italy-2020$3 ? \mathrm{r}=\mathrm{DE} \& \mathrm{IR}=\mathrm{T}[10.09 .2020]$.

${ }^{9}$ https://en.wikipedia.org/wiki/Lockdown [10.09.2020].

${ }^{10} \mathrm{https} / / / \mathrm{www}$.politico.eu/article/europes-coronavirus-lockdown-measures-compared/

11 https://www.businessinsider.com/countries-on-lockdown-coronavirus-italy-2020$3 ? \mathrm{r}=\mathrm{DE} \& \mathrm{IR}=\mathrm{T}[10.09 .2020]$.
} 
projected at $5.4 \%$ for 2021, which is about $6.5 \%$ lower than in pre-COVID-19 projections (IMF 2020). On the company level, the impacts are mostly related to supply and demand drops. More specifically, effects of the global pandemic cause supply chain interruptions and declines in demand leading to a reduced workload which causes effects on employment, which in some countries have been compensated by state-aids and through short-time work.

Taking the automotive industry as an example, which is one of the essential branches of the German economy, the pandemic was plunging the industry in both a demand and supply shock. In China, the world's largest market, for example, factories were closed until February 2020 and sales decreased dramatically by $80 \%$, and are after the first recovery still $50 \%$ below compared to the previous year ${ }^{12}$. However, it must also be said that the (German) automotive industry is also facing a number of other problems, and the current poor performance cannot be attributed solely to the pandemic. Overall, the industry is also under pressure due to mistakes in the past ("diesel gate") and developments in the area of climate protection and the expansion of alternative mobility concepts (electric mobility, hydrogen fuel cells) in connection with digitization and automation and an increasing share of shared-economy business models that have not been taken into account for too long. The fact, that there are (currently) multiple superimposing transformations and decision making takes place under conditions of complete uncertainty without a fundament of accurate data ("Knight'sche Unsicherheit”, Knight 2017/1921) makes it even more worrisome. Most challenges humankind is confronted with on various levels are considered as “(super-)wicked problems" (Levin et al. 2012; Rittel, Webber 1973). To put it very short, a wicked problem is a messy problem (Ackoff 1997), where no silver-bullet solution exists, standard-operation procedures are not appropriate and new approaches have quickly to be collaboratively developed, under the condition of uncertainty, to tackle a problem, which however cannot be finally solved. When applied to the pandemic, wickedness shows itself in different ways (Zizka 2020). As SARS-CoV-2 and the related disease is not fully understood, a vaccine is not available yet in a global scale and the future infection scenarios remain uncertain, there is no definite problem

12 https://www.deutschlandfunk.de/coronavirus-und-die-autoindustrie-nagelprobe-fuereine.2897.de.html?dram:article_id=473726 [10.09.2020]. 
formulation. The is no obvious stopping rule: as infections recently increase in a second wave, no one can be sure, when the pandemic will be over. There is no 'right' or 'wrong' and hence the number of approaches towards solutions is infinite. Each approach, however, is a "one-shot-operation" and there is no room for trial-and-error. This creates an awkward situation for decision-makers, as each decision can make the situation even worse.

It seems, therefore, that the CoViD-19 pandemic is a significant new member in the family of "wicked problems" and social messes (such as habitat destruction and dramatic loss of biodiversity, poverty or climate change), which appear open and nonlinear systems. As nobody knows when the pandemic will end and what direction it will take, in the absence of the "right thing to do" and the fact, that trial-and-error comes at an unacceptably high cost, what is left is an incremental muddling through (Braybrooke et al. 1963; Lindblom 1959; Wildavsky 1973). This brings us back to the limitations of conventional risk management, as described above. The CoViD-19 pandemic is an event that could have been expected, but which came across the globe by surprise or unexpectedly, as otherwise countermeasures (e.g. stockpiling of face masks, sanitizers and disinfection agents, respirators) would have taken place. It seems that CoViD-19 is not precisely a black swan event, but a black elephant. The metaphor of the "elephant in the room" is widely used to describe an obvious problem, which is not addressed but instead ignored ${ }^{13}$. Insurance experts expect a pandemic every 20 years ${ }^{14}$ and potential threats of "the monsters at door" have been described at various places as existential risks (e.g. Casti 2012; Ord 2020; Taleb 2008). It is likely that pandemics are present in many standard risk inventories and response plans are developed for it, but they eke out fate in the filing cabinet or are actually repressed or ignored. The same seems to be true when it comes to the detection of early warnings: China reported the novel corona-virus outbreak end of 2019, and there are indications that the dangers were known earlier (Platje et al. 2020). Therefore, the

\footnotetext{
${ }^{13}$ A similar metaphor is the "green swan" which points to a high likely risk, which timing and occurrence is unknown and which properties and impacts are too complex to be fully understood (Bolton et al. 2020; Müller, Hornig 2020; Silva 2020).

$14 \mathrm{https} / /$ www.handelsblatt.com/finanzen/banken-versicherungen/gunther-kraut-pandemieexperte-der-munich-re-alle-20-bis-30-jahre-kann-so-etwas-wie-corona-

passieren/25770456.html?ticket=ST-527058-0edblFrcIrnadfmpii1K-ap4 [10.09.2020].
} 
question arises, why the possibility was not seen earlier (Müller, Hornig 2020), why it was an unseen evidence (Platje et al. 2020: 152). Van Dam and Webbink (2020) argue in this journal, that it is a matter of conscious ignorance, of buying into collateral damage, which is systemically embedded in the neo-liberal capitalist economic system (van Dam, Webbink 2020). The precautionary principle, which suggests that even a few indications should suffice to initiate preventive measures, is undermined in the neo-liberal logic. Instead, the authors assume that the problems that have become apparent in the supply of certain medical products and the provision of beds in intensive care units in recent months are almost inevitably the result of an economic system that places short-term corporate profit and shareholder interests above the common good. Van Dam and Webbink point out another interesting point, namely that concerning wicked-problems: "everyone can define the problem and its cause in one's own way to derive one's favourite solution to the problem. Whatever measure is implemented to counter the crisis can be labelled anything from overreacting and creating panic to ignoring the seriousness and wilful [sic!] negligence" (van Dam, Webbink 2020: 13). They see this aspect reinforced by policies put under pressure by public opinion: "Even more perversely an avoidable crisis that is managed successfully also scores better in the media than a manageable crisis that is avoided successfully." (van Dam, Webbink 2020: 13).

Although risk management and early warning systems are used in corporations, they seem to fail to detect short-term impacts on supply chain management and other business operations. When being confronted with low-probability and high impact black swan events, or unexpected but predicted events ("black elephants"), conventional approaches to risk management are limited (Murphy et al. 2020; Murphy, Conner 2012; Werther 2013). Hence it is recommended in this paper, to change the perspective towards a more preventive approach, i.e. business continuity, which aims to increase the resilience of operations. 


\section{Changing the perspective: prevention, business continuity and supply chain viability or resilience}

Given the limitations of risk management and the circumstance that the CoViD19 pandemic is a wicked black elephant, an event that its expected and unexpected at the same time (Platje et al. 2020), which causes severe socio-economic impacts and far-reaching consequences and where is no prescriptive and promising in the face of uncertainty and complexity except of "muddling through", alternative approaches to corporate risk management are needed. One approach to overcome the limitations of conventional probability-based risk management could be to change the perspective towards the prevention of assets and maintaining the effectiveness and to allow for a restart of critical infrastructures. As we have seen during the pandemic and the global lockdown, companies and other types of an organization rely on the effective functioning of infrastructures and supply chains. The interruption of critical and vital processes and infrastructures may represent an existentially threatening risk (Sheffi 2007). Two approaches are worth to be considered:

1. Reducing vulnerability, i.e. business continuity planning

2. Supply Chain Resilience

\section{Ad 1) Business Continuity Management}

Business continuity planning and management seeks to preserve or restore the capability of companies to achieve its mission, its operations in terms of delivery of products and services and its customer base and market share (Hiles 2010; Will, Brauweiler 2020 and the relevant international standards such as ISO 22300: 2018, and ISO 22301: 2019).

Business Continuity Planning involves several steps, where the Business Impact Analysis (BIA) and the development of BC strategies and measurements as well as trainings and exercises. It is crucial to identify critical assets, infrastructures and process, which are essential to keep operational productivity, e.g. IT systems, electricity as well as supply with urgently needed raw materials and materials or preliminary products. During an BIA the focus is on the effects not on the causes and 
their likelihood. The aim is to estimate the range of damage to specific and crucial assets concerning different effect categories (see Table 1)

\section{Table 1. Examples for effect categories related to vital assets are}

\begin{tabular}{|l|l|}
\hline $\begin{array}{l}\text { Loss of facility } \\
\text { infrastructures }\end{array}$ & $\begin{array}{l}\text { Offices, factories, warehouses and other physical structures and } \\
\text { tangible assets, that can become inaccessible or unusable (due to } \\
\text { floods, fires, chemical contamination, loss of power, condemnation } \\
\text { by inspectors etc.). }\end{array}$ \\
\hline $\begin{array}{l}\text { Loss if } \\
\text { information }\end{array}$ & $\begin{array}{l}\text { Equipment, machinery and office can always be replaced, while loss } \\
\text { of intangible assets such as information and intellectual property, } \\
\text { besides others, may irreversible. With the advent of cloud technology } \\
\text { and automated backups, the solutions to protecting information are } \\
\text { available to everyone }\end{array}$ \\
\hline $\begin{array}{l}\text { Disruption in } \\
\text { operations }\end{array}$ & $\begin{array}{l}\text { Labour strikes, supply chain breakdown, mass transit disruption, } \\
\text { pandemics and other events }\end{array}$ \\
\hline $\begin{array}{l}\text { Technology } \\
\text { disruption }\end{array}$ & $\begin{array}{l}\text { caused by hardware malfunction, cyber attack, network failure and } \\
\text { software issues }\end{array}$ \\
\hline $\begin{array}{l}\text { Organizational } \\
\text { disruptions }\end{array}$ & $\begin{array}{l}\text { that prevent organizations from fulfilling their obligations such as } \\
\text { legal, regulatory, intellectual property, bankruptcy and financial } \\
\text { malfeasance }\end{array}$ \\
\hline
\end{tabular}

Source: Hiles (2010).

When considering the impact of disruptions, BIA aims to estimate time frames concerning duration of interruption, the time period within the disruption becomes unacceptable and the desired recovery time. Metrics such as Maximum Tolerable Period of Disruption (MTPD), Minimum Business Continuity Objective (MBCO), and the Recovery Time Objective (RTO) are suggested by the relevant international standards ISO 22313 and ISO 22313 (see further descriptions in Hiles 2010; Will, Brauweiler 2020).

The metrics indicate the needs for recovery, which then shall serve as a basis for the allocation of funds in order to realize one or more direct responses to crisis or disruptions. Examples are (Will, Brauweiler 2020):

- Capacity reserves for production facilities, redundant processes, e.g. external backup data centres to avoid information blackouts, redundant and independent feeds of data, energy and material supply, collaboration with other companies or mutual aid agreements, double sourcing of critical materials and components, 
different alternative transport modes, replacement of vending machines by manpower, securing the availability of manpower by personnel leasing, satellite offices and teleworking-options.

- Substitution strategy of core functions for instance in headquarters, including management, finance and accounting department, personnel department, public relations department and a system of deputies.

- Stockpiling and inventory management raw materials, semi-finished products and energy to compensate for the interruption of supply and demand.

- Separation: Inventories of finished products that should be physically separated from production.

- Rapid replacement and substitute procurement.

- Estimate inventories along value chains, including finished goods, blocked goods, spare parts and parts with lower quality ratings. After-sale stocks might be used to bridge shortcomings.

\section{Table 2. Metrics for Business Continuity Planning}

\begin{tabular}{|l|l|}
\hline $\begin{array}{l}\text { Maximum } \\
\text { tolerable period of } \\
\text { disruption (MTPD) }\end{array}$ & $\begin{array}{l}\text { The MTPD of an certain activity takes into account the duration } \\
\text { after which the organization irrevocably suffers damage if the } \\
\text { critical processes for the delivery of goods or the provision of } \\
\text { services fail }\end{array}$ \\
\hline $\begin{array}{l}\text { Minimum business } \\
\text { continuity } \\
\text { objective (MBCO): }\end{array}$ & $\begin{array}{l}\text { MBCO refers to the minimum level of product or service quality } \\
\text { that is acceptable to the organization to still achieve its business } \\
\text { objectives during a disruption }\end{array}$ \\
\hline $\begin{array}{l}\text { Recovery Time } \\
\text { Objective (RTO): }\end{array}$ & $\begin{array}{l}\text { RTO relates to the capacity and the time within it is planned that an } \\
\text { activity or dependency is to be resumed, i.e. the period during } \\
\text { which a process can fail without significantly hampering business } \\
\text { activity. }\end{array}$ \\
\hline $\begin{array}{l}\text { Recovery point } \\
\text { objective (RPO): }\end{array}$ & $\begin{array}{l}\text { RPO refers to the point to which information or other inputs used } \\
\text { by an activity must be restored to enable the activity to operate on } \\
\text { resumption. }\end{array}$ \\
\hline
\end{tabular}

Source: Hiles (2010).

\section{Ad 2) Supply Chain Resilience}

Business Continuity Planning focuses mainly on on-site assets and critical infrastructures from $1^{\text {st }}$-Tier suppliers. However, as shown by the pandemic, it might also be necessary to take actions for mitigating supply chain interruptions as well as 
to build up resilience against future disruptions, in particular as it is uncertain but possible that a second global lockdown occurs (Alicke et al. 2020). In order to enhance supply chain resilience, further aspects can be considered (Alicke et al. 2020; Ivanov 2020; Ivanov, Dolgui 2020; Jansen 2009; Sheffi 2017, 2006):

1. Supply Chain Transparency builds on an inventory of critical components and their suppliers and aims at the identification of alternative sourcing options and the creation of "multitier supply chains". This step requires the involvement of tier-one suppliers to identify tier-two and beyond suppliers. Cooperation can take the form of information-sharing agreements which also allow for early-warning systems to monitor lead times and inventory levels. It might also include discussing Business Continuity Management with Tier-1-suppliers to establish recovery plans for particular suppliers and commodities. In case that Tier-1suppliers decide to refuse cooperation or do not have visibilities on their own supplies, triangulation from different information sources and business-data providers and databases might be necessary.

2. Redundancies: Having redundancies, i.e. a plan $\mathrm{B}^{15}$, is an obvious strategy to protect against interruptions and to maintain services to customers while operations are being established. Organizations need redundancies - in the capital, in suppliers, in production capacity - to overcome crises. To protect themselves against small fluctuations, organizations have set up emergency storage facilities or maintain redundant technical systems. However, it was precisely these buffers that were intended to avoid waste through cost-fixed consultants and the lean management principle with tightly meshed logistics chains It is also important not to reverse the advantages of lean management and, despite this, to ensure a certain degree of crisis resilience. The basic forms of redundancy lie in the dual design of critical infrastructures (i.e. emergency power supply, IT systems, backups) and also in additional stocks of parts, materials or raw materials (i.e. SOSO-strategy: "sell one, stock one", Sheffi 2006: 190). While the creation of artificial buffers for tightly coupled and complex systems is a sensible measure, keeping capacities

\footnotetext{
${ }^{15}$ Or even no plan... The capacity to develop plans and grab opportunities to quickly adapt to external disruptions seems to be a key (see Platje et al. 2019).
} 
that are largely unused is very expensive and profit-oriented companies can hardly afford this. It is therefore necessary to proceed with a sense of proportion and to look for optimal ways to increase resilience

3. Assessment of customer demand: It is the core activity and at the same time the greatest challenge of supply chain management to forecast future customer demand with sufficient lead time. Complex statistical models and forecasting methods are often used for this purpose, but they always have uncertainty and are less suitable in the event of low-probability events. As has been well seen in the current case, crises may increase or decrease demand for particular products. Shortage-buying of consumables that are perceived to be short on supply may sends demand signals, which are unrealistic in the long term. Hence, besides advanced statistical forecasting, more dynamic forms of monitoring are recommended in order to react to inaccuracies (Alicke et al. 2020). This includes to use market information from business intelligence providers as well as reaching out directly to customers. Another aspect is to increase flexibility by replaceability of parts, postponement and a triage approach to initially serve only the most important customers (i.e. by strategic importance, margin, revenue).

In addition to the short- and mid-term measures described, it is also recommended to utilize scenario planning to estimate the potential implications of a prolonged or second-wave lockdown. On the basis on the information gathered during Business Continuity Planning, a cross-functional task force (with representatives from marketing and sales, operations, and strategy) can estimate other impacts in critical resources and business units in order to develop response strategies.

\section{Conclusion}

The whole history of humanity can be described as an attempt to tame existential uncertainties and threats, e.g. in the form of wild animals, forces of nature, diseases or war, and the desire to transform them into security. Entire sciences such as economics try to convert uncertain risks into probabilities and foreseeable developments - and then everything often turns out quite differently. 
The paper aimed to discuss the limitations of conventional risk management critically. It has argued, that the estimation of probabilities for the occurrence of risks and consequences fails concerning black-swan events and also black elephant-type of events, which could be expected but still are ignored. Uncertainty can never be eliminated entirely, and solutions often bring unexpected side effects. Hence there is an "illusion of certainty", which is mainly triggered by conventional risk management approaches, but fail under circumstances as described. The paper has shown from the theoretical perspective of the Normal Accident Theory, that in complex tightly coupled systems, organizational structures are prone to disruptions: are virtually inevitable. Taking the recent CoViD-19 and the global lock down in early 2020 as an example, it is argued, that the pandemic is a black-elephant type of event. This means, that pandemics could be expected, their occurrence is not surprising, but often ignored. The findings of the paper suggest, that risk management could be shifted from the estimation of probabilities and cause-effects chains towards a more preventive approach. Business continuity management considers critical processes and focusses on preventive measures for rapid recovery and restart. The findings will be of interest mainly for decision-makers and risk managers, who often rely on naïve approaches to risk management. This new understanding should help to improve preparations for supply chain interruptions and other impacts of global pandemics. The argumentation of this study is limited, as further research on examples for successful recovery of supply chain interruptions of global supply chains is outstanding. It can also be argued that concerning black-swan-preventive measures, it might be rational to ignore this sort of events, as otherwise, a cognitive overload could occur. In principle, the costs of appropriate prevention measures are infinite, because with sufficient imagination, one can imagine ever more fantastic horror scenarios ("space mutant hamsters conquer the world"). This would be a fruitful area for further work, which might explore in which way rational ignorance can lead to the identification of credible worst cases. 


\section{Acknowledgments}

The author thanks the CEREM Editor-in-chief, Prof. Johannes (Joost) Platje (WSB University in Wrocław, Poland) for profound critical and inspiring discussions on risk management and black swans in recent years and for encouraging me to summarise and publish his thoughts. I am also indebted to the two anonymous reviewers, whose constructive comments contributed significantly to the improvement of the manuscript. The paper was made possible by the support of the University of Applied Sciences Zittau/Görlitz, where I have been teaching the subject "Risk Management" for ten years.

\section{References}

Ackoff R.L. (1997), Systems, messes and interactive planning, "The Societal Engagement of Social Science", vol. 3, pp. 417-438.

Adam D. (2020), Special report. The simulations driving the world's response to COVID-19, "Nature", no. 580, pp. 316-318.

Ale B.J.M., Hartford D.N.D., Slater D. (2015), ALARP and CBA all in the same game, "Safety Science”, no. 76 , pp. $90-100$.

Alicke K., Azcue X., Barriball E. (2020), Coronavirus's impact on supply chain, McKinsey, https://www.mckinsey.com/business-functions/operations/our-insights/supply-chain-recovery-incoronavirus-times-plan-for-now-and-the-future [22.09.2020].

Atkeson A. (2020), What will be the economic impact of CoViD-19 in the US? Rough estimates of disease scenarios, Working Paper No. 26867, National Bureau of Economic Research, Los Angeles.

Aven T. (2020), Three influential risk foundation papers from the 80s and 90s. Are they still state-ofthe-art?, "Reliability Engineering \& System Safety", vol. 193, https://www.sciencedirect.com/science/article/pii/S0951832019302649 [22.09.2020].

Balog-Way D.H.P., McComas K.A. (2020), CoViD-19: reflections on trust, tradeoffs, and preparedness, "Journal of Risk Research", https://doi.org/10.1080/13669877.2020.1758192.

Banse G., Bechmann G. (2013), Interdisziplinäre Risikoforschung. Eine Bibliographie, VS Verlag für Sozialwissenschaften, Wiesbaden.

Beck U. (1988), Gegengifte. Die organisierte Unverantwortlichkeit, Suhrkamp, Berlin.

Beck U. (1992), From industrial society to the risk society. Questions of survival, social structure and ecological enlightenment, "Theory, Culture \& Society”, vol. 9 no. 1, pp. 97-123.

Beck U. (1992), Risk society. Towards a new modernity, Sage Publications, London. 


\section{THE COVID-19 PANDEMIC AND THE END OF CORPORATE RISK MANAGEMENT ...}

Bolton P., Luiz M., Pereira A., Silva D., Samama F., Svartzman R. (2020), The green swan. Central banking and financial stability in the age of climate change, https://www.bis.org/publ/othp31.pdf [22.09.2020].

Braybrooke D., Lindblom C.E., Coaut L.C. (1963), A strategy of decision. Policy evaluation as a social process, Free Press, Glencoe.

Casti J.L. (2012), X-events. The collapse of everything. William Morrow, New York.

Chalmers A. (2013), What is this thing called science? University of Queensland Press, Brisbane.

Chawla S., Lenka U. (2018), Leadership in VUCA environment, in: Flexible strategies in VUCA markets, Dhir S., Sushil (eds.), Springer, Singapore, pp. 213-224.

Cheng C., Barceló J., Hartnett A.S., Kubinec R., Messerschmidt L. (2020), CoViD-19 government response event dataset (CoronaNet v.1.0), "Nature Human Behaviour", vol. 4, pp. 756-768.

Choi T.Y., Wu Z. (2009), Triads in supply networks. Theorizing buyer-supplier-supplier relationships, "Journal of Supply Chain Management", vol. 45, pp. 8-25.

Davies N.G., Kucharski A.J., Eggo R.M., Gimma A., Edmunds W.J., Jombart T., O’Reilly K., Endo A., Hellewell J., Nightingale E.S., Quilty B.J., Jarvis C.I., Russell T.W., Klepac P., Bosse N.I., Funk S., Abbott S., Medley G.F., Gibbs H., Pearson C.A.B., Flasche S., Jit M., Clifford S., Prem K., Diamond C., Emery J., Deol A.K., Procter S.R., Zandvoort K. van, Sun Y.F., Munday J.D., Rosello A., Auzenbergs M., Knight G., Houben R.M.G.J., Liu Y. (2020), Effects of non-pharmaceutical interventions on CoViD19 cases, deaths, and demand for hospital services in the UK. A modelling study, "The Lancet Public Health", no. 5, pp. e375-e385.

Dehning J., Zierenberg J., Spitzner F.P., Wibral M., Neto J.P., Wilczek M., Priesemann V. (2020a), Inferring change points in the spread of COVID-19 reveals the effectiveness of interventions. "Science", vol. 369 no. 6500 .

Dehning J., Zierenberg J., Spitzner F.P., Wibral M., Neto J.P., Wilczek M., Priesemann V. (2020b), Inferring change points in the spread of COVID-19 reveals the effectiveness of interventions. "Science" vol. 369 no. 6500 .

Dörner D. (1997), The logic of failure. Recognizing and avoiding error in complex situations, AddisonWesley, Boston.

Douglas M.A., Widavsky A. (1983), Risk and culture. An essay on the selection of technological and environment dangers, University of California Press, Berkeley.

Dyer J.H., Nobeoka K. (2000), Creating and managing a high-performance knowledge-sharing network: the Toyota case, "Strategic Management Journal", vol. 21 no. 3, pp. 345-367.

Farmer F.R. (1967), Siting criteria. A new approach, International Atomic Energy Agency (IAEA), Wienna.

Ganz C., Deuerler F. (2011), Die Risikoanalyse mittels Konsequenz und Eintrittswahrscheinlichkeit, Methodik am Beispiel des Druckbehaelterversagens. Teil 1: Konsequenz, Teil 2: Eintrittswahrscheinlichkeit, Springer, Berlin. 
Glassman R.B. (1973), Persistence and loose coupling in living systems, "Behavioral Science", vol. 18 no. 2, pp. 83-98.

Guerrieri V., Lorenzoni G., Straub L., Werning I. (2020), Macroeconomic implications of CoViD-19. Can negative supply shocks cause demand shortages?, Working Paper No. 26918, National Bureau of Economic Research, Los Angeles.

Hiles A. (2010), The definitive handbook of business continuity management, Wiley, New York.

Hoskisson R.E., Chirico F., Zyung J. (Daniel), Gambeta E. (2016), Managerial risk taking. A multitheoretical review and future research agenda, "Journal of Management", vol. 43 no. 1, pp. 137169.

Hume D., Steinberg E. (1993), An enquiry concerning human understanding; [with] A letter from a gentleman to his friend in Edinburgh; [and] an abstract of a Treatise of human nature, Hackett Publishing Company, Indianapolis.

IMF (international Monetary Fund) (2020), World Economic Outlook Update, June 2020. A crisis like no other, an uncertain recovery, https://www.imf.org/en/Publications/WEO/Issues/2020/06/24/WEOUpdateJune2020 [10.09.2020].

Ioannidis J.P.A. (2020), Coronavirus disease 2019. The harms of exaggerated information and nonevidence-based measures, "European Journal of Clinical Investigation", vol. 50 no. 4.

Ivanov D. (2020), Viable supply chain model. Integrating agility, resilience and sustainability perspectives - lessons from and thinking beyond the COVID-19 pandemic, "Annals of Operation Research", https://link.springer.com/article/10.1007\%2Fs10479-020-03640-6 [22.09.2020].

Ivanov D., Dolgui A. (2020), Viability of intertwined supply networks. Extending the supply chain resilience angles towards survivability. A position paper motivated by COVID-19 outbreak. "International Journal of Production Research", vol. 58 no. 10, pp. 2904-2915.

Jansen S. (2009), Im Feuer, "brand eins - Wirtschaftsmagazin", no. 2, https://www.brandeins.de/magazine/brand-eins-wirtschaftsmagazin/2009/kommunikation-pr/im-feuer [22.09.2020].

Jasanoff S. (1999), The songlines of risk, "Environmental Values”, vol. 8 no. 2, pp. 135-152.

Jones-Lee M., Aven T. (2011), ALARP - what does it really mean?, "Reliability Engineering \& System Safety", vol. 96 no. 8, pp. 877-882.

Jonkman S.N., van Gelder P.H.A.J.M., Vrijling J.K. (2003), An overview of quantitative risk measures for loss of life and economic damage, "Journal of Hazardous Materials", vol. 99 no. 1, pp. 1-30.

Kaplan S., Garrick B.J. (1981), On the quantitative definition of risk, "Risk Analysis", vol. 1 no. 1, pp. 11-27.

Kelly D.L., Smith C.L. (2009), Bayesian inference in probabilistic risk assessment. The current state of the art, "Reliability Engineering \& System Safety", vol. 94 no. 2, pp. 628-643.

Knight F. (2017), Risk, uncertainty and profit. New edition, Vernon Art and Science Incorporated, Wilmington. 


\section{THE COVID-19 PANDEMIC AND THE END OF CORPORATE RISK MANAGEMENT ...}

Levin K., Cashore B., Bernstein S., Auld G. (2012), Overcoming the tragedy of super wicked problems. Constraining our future selves to ameliorate global climate change, "Policy Science", vol. 45, pp. 123152.

Lindblom C.E. (1959), The science of "muddling through", "Public Administration Review", vol. 19 no. 2, pp. 79-88.

Ludvigson S.C., Ma S., Ng S. (2020), CoViD-19 and the macroeconomic effects of costly disasters, Working Paper No. 26987, National Bureau of Economic Research, Los Angeles.

March J.G., Shapira Z. (1987), Managerial perspectives on risk and risk taking, "Management Science", vol. 33 no. 1, pp. 1404-1418.

McAleer M. (2020), Prevention is better than the cure. Risk management of CoViD-19, "Journal of Risk and Financial Management”, vol. 13 no. 3, p. 46.

McKibbin W.J., Fernando R. (2020), The global macroeconomic impacts of CoViD-19. Seven scenarios, SSRN Scholarly Paper No. ID 3547729, Social Science Research Network, Rochester, NY.

Melchers R.E. (2001), On the ALARP approach to risk management, "Reliability Engineering \& System Safety", vol. 71 no. 2, pp. 201-208.

Müller H., Hornig N. (2020), Expecting the unexpected. A new Uncertainty Perception Indicator (UPI) - concept and first hesults, https://eldorado.tudortmund.de/bitstream/2003/39171/1/DoCMA_Working_Paper_1_\%2017-06-2020.pdf [22.09.2020].

Murphy J.F., Conner J. (2012), Beware of the black swan. The limitations of risk analysis for predicting the extreme impact of rare process safety incidents, "Process Safety Progress", vol. 31 no. 4, pp. 330333.

Murphy J.F., Jones J., Conner J. (2020), The CoViD-19 pandemic. Is it a "Black Swan"? Some risk management challenges in common with chemical process safety, "Process Safety Progress", vol. 39 no. 2, e12160.

Nicola M., Alsafi Z., Sohrabi C., Kerwan A., Al-Jabir A., Iosifidis C., Agha M., Agha R. (2020), The socio-economic implications of the coronavirus pandemic (CoViD-19). A review, "International Journal of Surgery", vol. 78, pp. 185-193.

Ord T. (2020), The precipice. Existential risk and the future of humanity, Bloomsbury Publishing, London.

Perrow C. (1992), Normale Katastrophen. Die unvermeidbaren Risiken der Großtechnik, CampusVerlag, Frankfurt am Main.

Perrow C. (2004), A personal note on normal accidents, "Organization \& Environment", vol. 17 no. 1, pp. 9-14.

Perrow C. (2011), Normal accidents. Living with high risk technologies. Updated edition, Princeton University Press, Princeton. 
Pfluger, C., 2009. In der größten Sicherheit..., Zeitpunkt, https://www.zeitpunkt.ch/fileadmin/download/ZP_100/100_6-9_Sicherheit.pdf [23.09.2020].

Platje J., Harvey J., Rayman-Bacchus L. (2020), CoViD-19. Reflections on the surprise of both an expected and unexpected event, "CEREM - WSB University in Wrocław", vol. 4, no. 1, pp. 149-162.

Platje J., Will M., Van Dam Y.K. (2019), A fragility approach to sustainability - researching effects of education, "International Journal of Sustainability in Higher Education", vol. 20 no. 7, pp. 1220-1239.

Popper K. (2002), The logic of scientific discovery, Taylor \& Francis, Milton Park.

Renn O. (2007), Risiko: über den gesellschaftlichen Umgang mit Unsicherheit, Oekom-Verlag, München.

Renn O. (2014), Das Risikoparadox. Warum wir uns vor dem Falschen fürchten, Fischer Taschenbuch, Berlin.

Rittel H.W.J., Webber M.M. (1973), Dilemmas in a general theory of planning, "Policy Science", vol. 4, pp. 155-169.

Russell B. (2001), The problems of philosophy, Oxford University Press, Oxford.

Russell B. (2004), History of Western philosophy, Taylor \& Francis, Milton Park.

Sagan S.D. (2004), The problem of redundancy problem. Why more nuclear security forces may produce less nuclear security, "Risk Analysis", vol. 24 no. 4, pp. 935-946.

Saurin T.A., Rooke J., Koskela L. (2013), A complex systems theory perspective of lean production. "International Journal of Production Research", vol. 51 no. 19, pp. 5824-5838.

Sheffi Y. (2006), Worst-case-Szenario. Wie Sie Ihr Unternehmen auf Krisen vorbereiten und Ausfallrisiken mindern, Moderne Industrie Verlag, Landsberg am Lech.

Sheffi Y. (2007), The resilient enterprise. Overcoming vulnerability for competitive advantage, The MIT Press, Cambridge, MA.

Sheffi Y. (2017), The power of resilience. How the best companies manage the unexpected, The MIT Press, Cambridge, MA.

Silva da L.A.P. (2020), Green swan 2. Climate change and CoViD-19. Reflections on efficiency versus resilience, https://monasia.mc/en/green-swan-2-climate-change-and-covid-19-reflections-on-efficiencyversus-resilience/ [23.09.2020].

Skilton P.F., Robinson J.L. (2009), Traceability and normal accident theory. How does supply network complexity influence the traceability of adverse events?, "Journal of Supply Chain Management", vol. 45 no. 3 , pp. 40-53.

Soliman M., Saurin T.A., Anzanello M.J. (2018), The impacts of lean production on the complexity of socio-technical systems, "International Journal of Production Economics", vol. 197, pp. 342-357. 


\section{THE COVID-19 PANDEMIC AND THE END OF CORPORATE RISK MANAGEMENT ...}

Starr C., Rudman R., Whipple C. (1976), Philosophical basis for risk analysis, "Annual Review of Energy", vol. 1, pp. 629-662.

Taleb N.N. (2008), The black swan. The impact of the highly improbable, Penguin Books, New York.

Van Dam Y.K., Webbink J.F. (2020), Reflecting on reflections on CoViD-19, "CEREM - WSB University in Wrocław", vol. 4 no. 2, pp. 7-19.

Vester F. (2012), The art of interconnected thinking. Ideas and tools for a new approach to tackling complexity, MCB-Verlag, München.

Weick K.E. (1976), Educational organizations as loosely coupled systems, "Administrative Science Quarterly", vol. 21 no. 1, pp. 1-19.

Weick K.E. (1996), Drop your tools. An allegory for organizational studies, "Administrative Science Quarterly", vol. 41 no. 2, pp. 301-313.

Weick K.E. (2016), Normal accident theory as frame, link, and provocation, "Organization \& Environment", vol. 17 no. 1, pp. 27-31.

Weick K.E., Sutcliffe K.M. (2011), Managing the unexpected. Resilient performance in an age of uncertainty, Wiley, Hoboken.

Weick K.E., Sutcliffe K.M., Obstfeld D. (1999), Organizing for high reliability. Processes of collective mindfulness, "Research in Organizational Behavior", vol. 21, pp. 81-123.

Werther G.F.A. (2013), When black swans aren't. On better recognition, assessment, and forecasting of large scale, large impact, and rare event change. "Risk Management and Insurance Review", vol. 16 no. 1 , pp. 1-23.

Wieler L., Rexroth U., Gottschalk R. (2020), Emerging CoViD-19 success story. Germany's strong enabling environment, Our World in Data, https://ourworldindata.org/covid-exemplar-germany [11.09.2020].

Wildavsky A. (1973), If planning is everything, maybe it's nothing. "Policy Science", vol. 4, pp. 127153.

Will M., Brauweiler J. (2020), Business continuity planning, in: Sustainable cities and communities, Leal Filho W., Marisa Azul A., Brandli L., Gökçin Özuyar P., Wall T. (eds.), Springer International Publishing, Cham, pp. 33-44.

Wilson R., Crouch E.A.C. (2001), Risk-benefit analysis, Department of Physics Series, Harvard Center for Risk Analysis, Cambridge.

Zio E. (2018), The future of risk assessment, "Reliability Engineering \& System Safety", vol. 177, pp. 176-190.

Zizka L. (2020), Coronavirus crisis communication: a wicked problem, https://hospitalityinsights.ehl.edu/covid19-crisis-communication [10.09.2020]. 